\title{
Infección materno-fetal por SARS-CoV-2
}

\author{
Maternal-fetal SARS-CoV-2 infection
}

Paula Ximena Losada Venegas,* Saúl Hernando Vallejo Chaves, ${ }^{* \neq}$ Fanny Esther Portilla Álvarez, ${ }^{\ddagger}$

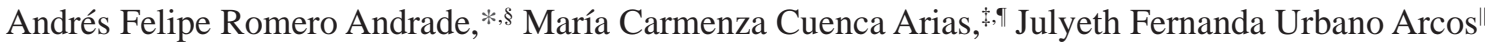

\footnotetext{
* Programa de Medicina, Facultad de Salud, Universidad Surcolombiana. Neiva, Huila, Colombia.

₹ Servicio de Pediatría, Clínica UROS. Neiva, Huila, Colombia.

§ Servicio de Infectología Pediátrica, Clínica UROS. Neiva, Huila, Colombia.

ๆ Unidad de Cuidados Intensivos Neonatales, Clínica UROS. Neiva, Huila, Colombia.

" Especialización en Pediatría, Universidad Libre Seccional Cali. Especialización en Epidemiología Universidad Autónoma de Bucaramanga. Colombia.
}

\section{RESUMEN}

La infección por SARS-CoV-2 ha estancado al mundo entero, es un virus relativamente nuevo del que poco se conoce, debido a su comportamiento en pocos meses llegó a convertirse en un problema de salud pública hasta catalogarse como evento pandémico por su alto grado de contagiosidad. Los esfuerzos tanto clínicos como epidemiológicos se han concentrado en entender su comportamiento para frenar su diseminación y tratar los efectos en la humanidad. Hasta el momento, es poco lo que se conoce sobre la infección materno-fetal o la posibilidad de transmisión vertical. Se reporta caso de COVID-19 en edad neonatal con prueba rRT-PCR para SARS-CoV-2 positiva, cuya madre fue diagnosticada con la misma enfermedad previo a su nacimiento luego de presentar síntomas respiratorios, además de una breve revisión de la literatura sobre la enfermedad.

Palabras clave: COVID-19, SARS-CoV-2, neonatal, embarazo, transmisión vertical.

\section{INTRODUCCIÓN}

Una nueva especie de coronavirus denominada SARS-CoV-2, por sus siglas en inglés «Severe Acute Respiratory Syndrome Coronavirus 2", es el más joven de una familia de siete cepas, está considerado entre los tres primeros lugares en esta familia por su alta contagiosidad y por ser causante de enfermedad grave. Surgió como un brote zoonó-

Citar como: Losada VPX, Vallejo CSH, Portilla ÁFE, Romero AAF, Cuenca AMC, Urbano AJF. Infección materno-fetal por SARS-CoV-2. Rev Latin Infect Pediatr. 2021; 34 (2): 100-105. https://dx.doi. org/10.35366/100549

Recibido: 15-01-2021. Aceptado: 23-02-2021.

Rev Latin Infect Pediatr. 2021; 34 (2): 100-105
ABSTRACT

The SARS-CoV-2 infection has stalled the entire world, it is a relatively new virus of which little is known due to its behavior in a few months it became a public health problem to the extent of being classified as a pandemic event due to its high degree of contagiousness. Both clinical and epidemiological efforts have focused on understanding its behavior to slow its spread and address the effects on humanity. So far, little is known about maternal-fetal infection or the possibility of vertical transmission. A case of COVID-19 in neonatal age with a positive rRT-PCR test for SARS-CoV-2 is reported whose mother was diagnosed with the disease prior to birth after presenting respiratory symptoms. Along with a brief review of the literature on the disease.

Keywords: COVID-19, SARS-CoV-2, neonatal, pregnancy, vertical transmission.

tico en una pequeña ciudad de China en diciembre de 2019. La enfermedad por coronavirus (COVID19) es de fácil y rápida transmisión, por lo que en marzo de 2020 la Organización Mundial de la Salud (OMS) declaró una alerta sanitaria mundial y estado de pandemia. ${ }^{\dagger}$ A pesar de que en Colombia se han tomado estrictas medidas sanitarias para controlar y evitar la rápida propagación, los contagios se reportan en aumento.

EI SARS-CoV-2 pertenece al género Betacoronavirus, un conjunto de virus caracterizados por ocasionar cuadros de neumonía grave al igual que otros pertenecientes a la familia de coronavirus, como es el caso de SARS-CoV-1 y MERS-CoV que son responsables de síndromes respiratorios

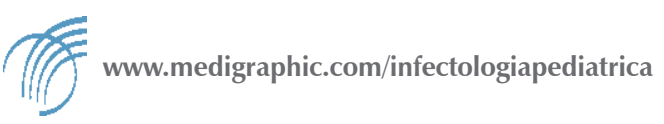


agudos graves, que además involucran diversos órganos y sistemas, desencadenados por una tormenta de citoquinas en respuesta a la infección, lo cual genera una alta morbimortalidad en la población, en especial aquellas con condiciones preexistentes. ${ }^{1}$ La tasa de letalidad del SARS-CoV-2 en la población general es de $4.3 \%$ en promedio (llegando a superar el $10 \%$ según la fase epidemiológica), la cual es relativamente baja en comparación con otros coronavirus, pero a diferencia del resto es altamente contagioso y se han descrito muchas formas de contagio.?

La información disponible sobre el efecto de la infección por COVID-19 en el feto es limitada y por consiguiente la transmisión vertical madre-hijo es aún motivo de estudio. Las mujeres embarazadas son consideradas una población de alto riesgo debido a su condición inmunológica desde que inicia la gestación y, por lo tanto, se vislumbran más complicaciones como ruptura prematura de membranas, trabajo de parto pretérmino, muerte fetal intrauterina, restricción del crecimiento intrauterino, muerte neonatal, entre otras. ${ }^{3}$

Se reporta caso de COVID-19 en etapa neonatal temprana con rRT-PCR (real-time reversetranscription polymerase chain reaction) positiva a partir de una muestra de aspirado traqueal en las primeras 24 horas de vida, producto de una madre sintomática cuya infección fue confirmada mediante el mismo método diagnóstico a las 33 semanas de gestación.

\section{PRESENTACIÓN DEL CASO}

La madre del neonato es una paciente de 33 años de edad con antecedente de dos gestaciones previas, un parto normal y un aborto de causa desconocida. Como antecedentes patológicos padece de vitíligo que controla con terapia farmacológica. Reside y procede de zona rural de Colombia, donde para la fecha ya existían casos para esta patología. ${ }^{4}$

A las 32 semanas de gestación la madre presentó cuadro de tos productiva, dificultad respiratoria progresiva, fiebre subjetiva asociada con escalofríos, astenia, adinamia y mialgias, por lo que decide asistir al centro primario de salud. Por compromiso respiratorio y condición epidémica deciden tamizar para COVID-19, toman muestra de hisopado nasofaríngeo para prueba confirmatoria de SARS-CoV-2. Por deterioro respiratorio se decide realizar radiografía de tórax (Figura 1) seguida de tomografía computarizada de tórax (Figura 2) en las cuales se evidencian infiltrados tipo vidrio esmerilado bilaterales patognomónicos de infección por el nuevo coronavirus. Se inicia manejo farmacológico con antibiótico de amplio espectro y se remite a una institución de mayor complejidad de atención.

Ingresa a centro de mayor complejidad, clínicamente estable, con persistencia de síntomas respiratorios y con requerimiento de oxígeno suplementario a bajo flujo, sin evidencia de signos de respuesta inflamatoria sistémica, gases arteriales reflejan
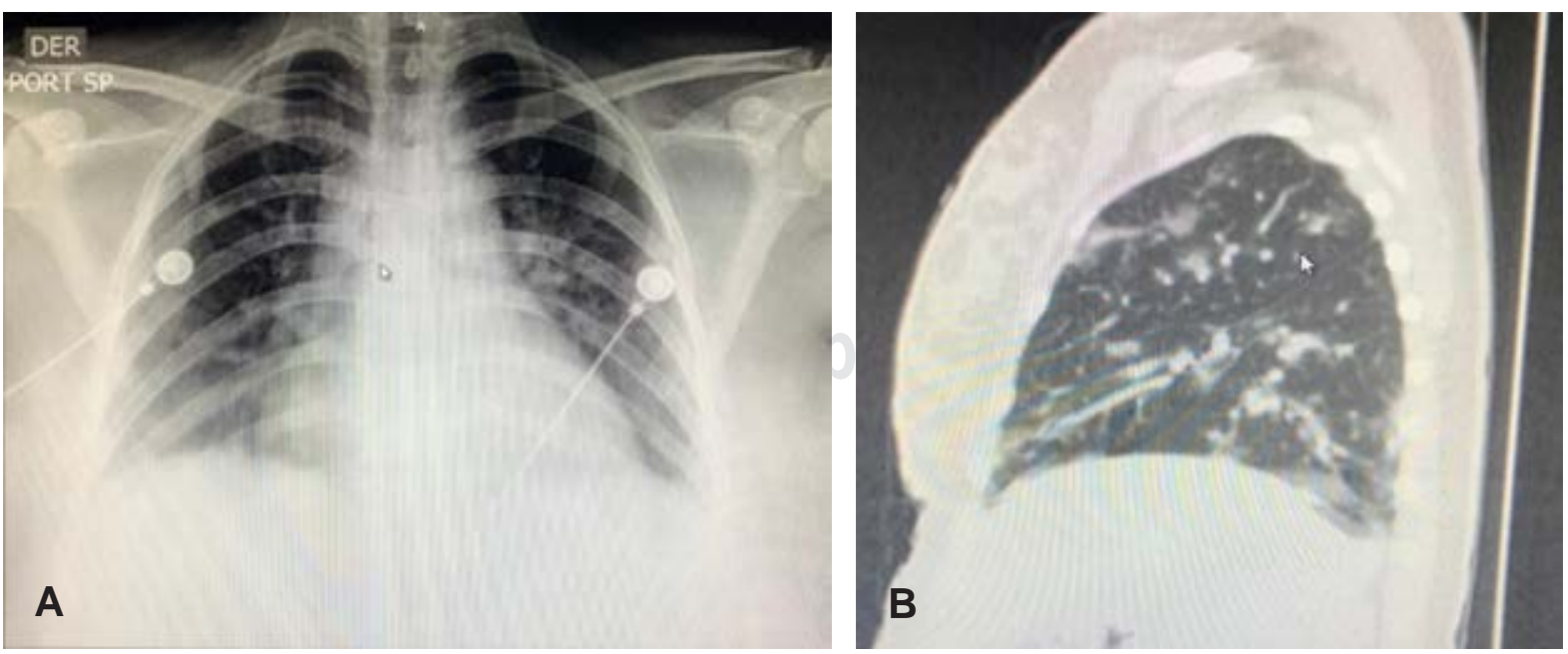

Figura 1: Radiografía de tórax de la madre del recién nacido, A) anteroposterior y B) lateral, con adecuada técnica, en las cuales se observan infiltrados intersticiales bilaterales, silueta cardiaca conservada, sin otros hallazgos. 


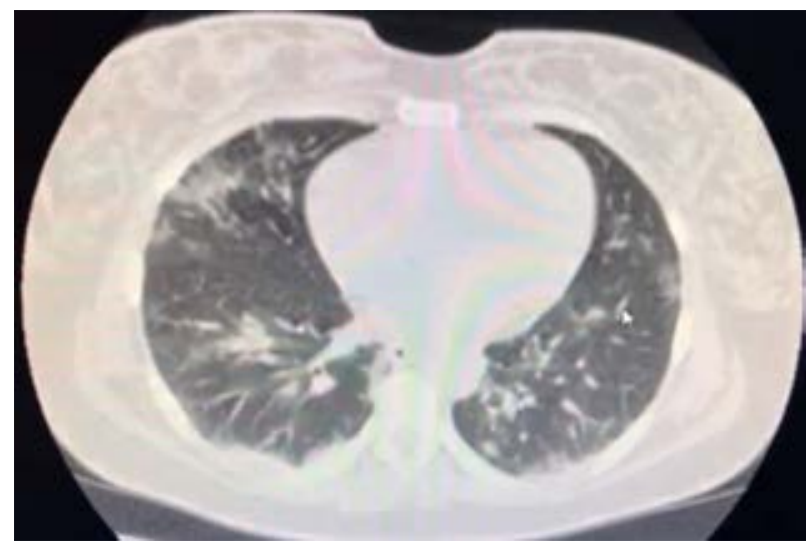

Figura 2: Se muestra TAC de tórax con aumento marcado de la densidad y parcheado difuso en vidrio esmerilado en todos los cuadrantes de tipo periférico. La tráquea y los bronquios son de curso y calibre normales. La silueta cardiotímica es de tamaño y forma normal, la aorta y la vascularización pulmonar no presentan alteraciones. No se identifican masas ni adenomegalias mediastinales.

acidosis metabólica sin trastorno de la oxigenación. En el contexto global de la pandemia por COVID-19, ingresa como neumonía viral sospechosa de infección por SARS-CoV-2, se clasifica como embarazo de alto riesgo e ingresa a la Unidad de Cuidados Intensivos (UCI). Durante su estadía en la UCI se confirma la infección mediante el reporte de rRT-PCR realizada en el sitio de referencia. El Servicio de Ginecología realiza pruebas de bienestar fetal que muestran perfil biofísico $8 / 8$ y ecografía obstétrica con feto único vivo, monitoreo ACOG I sin documentación de actividad uterina.

Con evolución insatisfactoria se registra monitoreo fetal ACOG II, con línea de base 162 lpm (latidos por minuto) con movimientos fetales presentes y sin evidencia de actividad uterina. Se considera que cursa con un estado fetal no tranquilizador y se realiza reanimación in utero. El mismo día, en horas de la tarde, se realiza nuevo monitoreo fetal en el que persistió la taquicardia (ACOG II, línea de base 166 lpm) sin respuesta al manejo establecido, por lo que se realiza cesárea de urgencia. Bajo todas las medidas de protección ordenadas por la OMS se obtiene recién nacido de sexo femenino, líquido amniótico normotérmico, placenta, anexos normales. Se envía la placenta para análisis patológico, el cual describe ausencia de infiltrado inflamatorio agudo sin signos de villitis ni lesiones intervellositarias.

Se trata de recién nacido prematuro de 33 semanas, presenta adaptación neonatal espontánea con
Apgar: 8/10-9/10-10/10, antropometría: peso 2,320 $\mathrm{g}$, talla $44 \mathrm{~cm}$, perímetro cefálico $32 \mathrm{~cm}$, perímetro torácico $20 \mathrm{~cm}$, perímetro abdominal $29 \mathrm{~cm}$. Con incremento progresivo de dificultad respiratoria y aumento de los requerimientos de $\mathrm{FiO}_{2}$, se inicia soporte ventilatorio invasivo e intubación de acuerdo con el protocolo para COVID-19 del Ministerio de Salud y Protección Social de Colombia. ${ }^{5}$ Requiere una dosis de surfactante pulmonar y por condición se tomó muestra de aspirado traqueal para estudio diagnóstico de SARS-CoV-2 en las primeras 24 horas de vida con reporte positivo para COVID-19 por rRT-PCR 10 días después de su nacimiento.

La radiografía de tórax (Figura 3) reveló leves opacidades reticulares centrales con adecuado volumen pulmonar sin indicación de segunda dosis de surfactante pulmonar. Una segunda tomografía de tórax (Figura 4) muestra signos de consolidación en base pulmonar izquierda, por lo cual recibió manejo con ampicilina y gentamicina. Sin embargo, los hemocultivos fueron negativos, por lo cual se completó manejo durante cinco días de tratamiento. Tres días después se retira soporte ventilatorio con adecuada evolución, tras 14 días de asilamiento según protocolos, se decide egreso en apoyo con programa canguro extrainstitucional junto a su madre que también tuvo una buena evolución.

\section{DISCUSIÓN}

En Colombia, luego del primer caso reportado de COVID-19, se ha visto un incremento de casos de

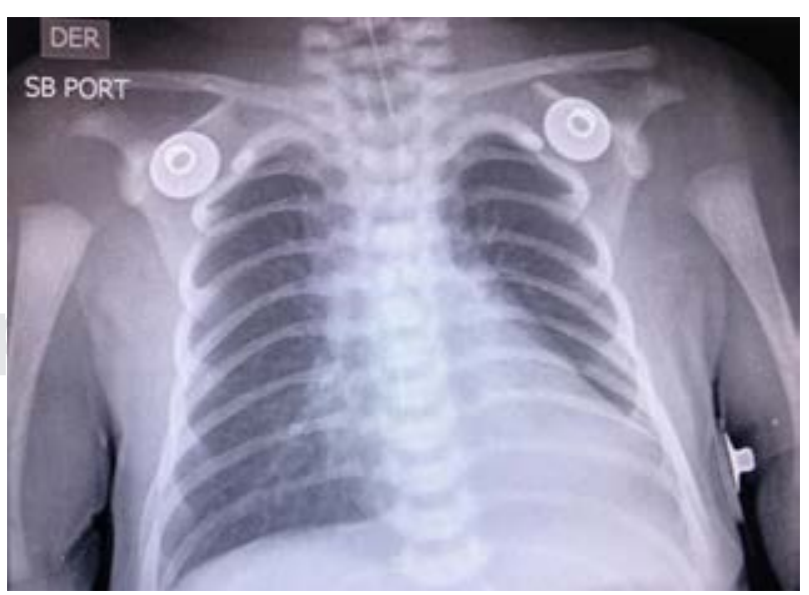

Figura 3: Radiografía de tórax del recién nacido, con mala técnica, rotada, impresiona silueta cardiaca aumentada de tamaño con opacidades reticulares centrales sin alteraciones en tejidos óseos. 


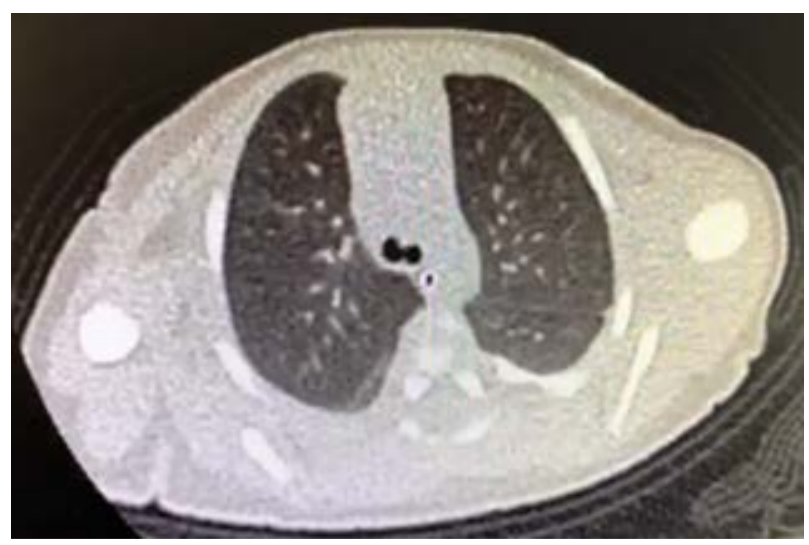

Figura 4: Tomografía axial computarizada de tórax de recién nacido con aumento de la densidad y parcheado leve en vidrio esmerilado en cuatro cuadrantes de tipo periférico, sin evidencia de derrame ni engrosamiento pleural. Estructuras óseas y tejidos blandos sin alteraciones.

manera heterogénea en las diferentes regiones del territorio nacional. ${ }^{6}$ Dentro de los grupos más susceptibles a las infecciones respiratorias se encuentran las mujeres embarazadas y junto con ellas la posibilidad de transmisión vertical maternofetal. ${ }^{\text {. }}$

Se describe el caso de COVID-19 neonatal con alta sospecha de haber sido de transmisión perinatal y que corresponde a uno de los primeros casos de COVID-19 reportados en Colombia de transmisión vertical.

La transmisión postnatal es extremadamente improbable. No se realizó ningún procedimiento generador de aerosol en la madre durante la cesárea, además ésta llevaba mascarilla N95. La madre y el bebé fueron separados inmediatamente al nacimiento sin contacto hasta completar el aislamiento individual del recién nacido, además, se debe tener en cuenta que la toma de la PCR para SARS-CoV-2 del recién nacido fue realizada sin contacto previo con la madre. De igual manera, la transmisión al recién nacido por parte de algún trabajador de la salud infectado era poco probable, ya que el personal que atendió el nacimiento en salas de cirugía estuvo asintomático durante las dos semanas previas y posteriores al nacimiento y todo el personal en contacto con el neonato infectado durante la adaptación cumplió con los lineamientos para el manejo clínico de pacientes con infección por COVID-19 del Ministerio de Salud y Protección Social de Colombia. ${ }^{5}$

En la literatura se revela que la mayoría de los nacimientos de hijos de madres con COVID-19 fueron por cesárea y la indicación parece tener una causa obstétrica dada usualmente por trabajo de parto pretérmino, ruptura prematura de membranas y estado fetal no satisfactorio, ${ }^{8,9}$ tal como se muestra en la revisión del presente caso; sin embargo, resultados de metaanálisis demuestran que hasta el momento no existe una asociación entre COVID-19 y trabajo de parto pretérmino ni tampoco con la definición de la vía de parto. ${ }^{10}$

La mayoría de los estudios han usado rRT-PCR para SARS-CoV-2 para el diagnóstico de infección perinatal en el recién nacido y la toma de las muestras han sido de diferentes localizaciones como lo son el hisopado nasofaríngeo, hisopado rectal, sangre, entre otros. En el caso reportado se usó para el diagnóstico rRT-PCR la muestra del aspirado tomada a través del tubo orotraqueal. La mayoría de los recién nacidos analizados en la literatura, hijos de madre con infección confirmada por COVID-19, se reportan negativos; no obstante, existe un porcentaje muy bajo de casos que son positivos, por lo cual no se puede descartar del todo que exista transmisión perinatal. ${ }^{1}$

Diferentes teorías se han propuesto acerca de que la posibilidad de transmisión perinatal pueda ocurrir, un ejemplo sería el paso transplacentario al ocurrir la viremia inicial durante el curso de la enfermedad o del tropismo que la placenta pueda tener por el virus al tener en algún grado expresión del receptor de la enzima convertidora de angiotensina 2 (ACE2); ${ }^{12}$ sin embargo, aún no se demuestran a cabalidad estas teorías. En el caso presentado, el reporte de la patología placentaria no mostraba ningún hallazgo; no obstante, estudios iniciales sólo describen hallazgos de malperfusión vascular fetal en $47 \%$ de las placentas analizadas y en un porcentaje que no supera el $20 \%$ otros hallazgos inespecíficos como funisitis, villitis y malperfusión vascular materna. ${ }^{12,13}$

Pocos reportes sugieren que puede existir transmisión vertical de SARS-CoV-2 de la madre al recién nacido, de modo que la evidencia aún es incierta y se requieren más estudios para demostrarlo.

\section{CONCLUSIÓN}

Hasta el momento hay poca literatura disponible, por lo que se requiere un registro robusto y mayores investigaciones que ayuden a identificar más casos de transmisión vertical de COVID-19 para garantizar la atención oportuna del binomio madre-hijo y establecer directrices claras para su manejo. 


\section{REFERENCIAS}

1. Ashraf MA, Keshavarz $P$, Hosseinpour $P$ et al. Coronavirus disease 2019 (COVID-19): a systematic review of pregnancy and the possibility of vertical transmission. J Reprod Infertil. 2020; 21 (3): 157-168. http://www.ncbi.nlm.nih.gov/ pubmed/32685412.

2. Sun J, He WT, Wang L et al. COVID-19: epidemiology, evolution, and cross-disciplinary perspectives. Trends Mol Med. 2020; 26 (5): 483-495. doi: 10.1016/j. molmed.2020.02.008.

3. Melo GC, Araújo KCGM. COVID-19 infection in pregnant women, preterm delivery, birth weight, and vertical transmission: a systematic review and meta-analysis. Cad Saude Publica. 2020; 36 (7): e00087320. doi: 10.1590/0102$311 \times 00087320$.

4. Putumayo G. Secretaría de salud departamental Putumayo. Boletín epidemiológico COVID-19. Reporte 25-07-2020. 2020; 21 (1): 1-9.

5. Ministerio de Salud Colombia. Lineamientos para el manejo clínico de pacientes con infección por nuevo coronavirus COVID-19. Bogotá: Julio de 2020. Disponible en: https:// www.minsalud.gov.co/Ministerio/Institucional/Procesos y procedimientos/PSSS03.pdf.

6. Huila GDEL. Secretaría de Salud Departamental Boletín Epidemiológico No. 12 COVID-19 Huila-Reporte 30-03-2020 Casos confirmados Secretaría de Salud Departamental Seguimiento a Personas. 2020; (12): 19-21.

7. Karimi-Zarchi M, Neamatzadeh H, Dastgheib SA et al. Vertical transmission of coronavirus disease 19 (COVID-19) from infected pregnant mothers to neonates: a review. Fetal Pediatr Pathol. 2020; 39 (3): 246-250. doi: 10.1080/15513815.2020.1747120.

8. Khoury R, Bernstein PS, Debolt $C$ et al. Characteristics and outcomes of 241 births to women with severe acute respiratory syndrome coronavirus 2 (SARSCoV-2) infection at five New York City medical centers. Obstet Gynecol. 2020; 136 (2): 273-282. doi: 10.1097/ AOG.0000000000004025.

9. Wu YT, Liu J, Xu JJ et al. Neonatal outcome in 29 pregnant women with COVID-19: a retrospective study in Wuhan, China. PLoS Med. 2020; 17 (7): e1003195. doi: 10.1371/ journal.pmed.1003195.

10. Kotlyar AM, Grechukhina O, Chen A et al. Vertical transmission of coronavirus disease 2019: a systematic review and meta-analysis. Am J Obstet Gynecol. 2021; 224 (1): 35-53.e3. doi: 10.1016/j.ajog.2020.07.049.

11. Yoon SH, Kang JM, Ahn JG. Clinical outcomes of 201 neonates born to mothers with COVID-19: a systematic review. Eur Rev Med Pharmacol Sci. 2020; 24 (14): 7804 7815. doi: 10.26355/eurrev_202007_22285.

12. Baergen RN, Heller DS. Placental pathology in covid-19 positive mothers: preliminary findings. Pediatr Dev Pathol. 2020; 23 (3): 177-180. doi: $10.1177 / 1093526620925569$.

13. Zaigham M, Andersson $O$. Maternal and perinatal outcomes with COVID-19: a systematic review of 108 pregnancies. Acta Obstet Gynecol Scand. 2020; 99 (7): 823-829. doi: 10.1111/aogs.13867.

Financiamiento: Ninguno.

Conflicto de intereses: Ninguno.

Correspondencia:

Julyeth Fernanda Urbano Arcos

Especialización en Pediatría,

Universidad Libre Seccional Cali,

Cali, Valle del Cauca, Colombia.

Tel: +57 32 3545-4513

E-mail: jfurbanoa@gmail.com 
Anexo.

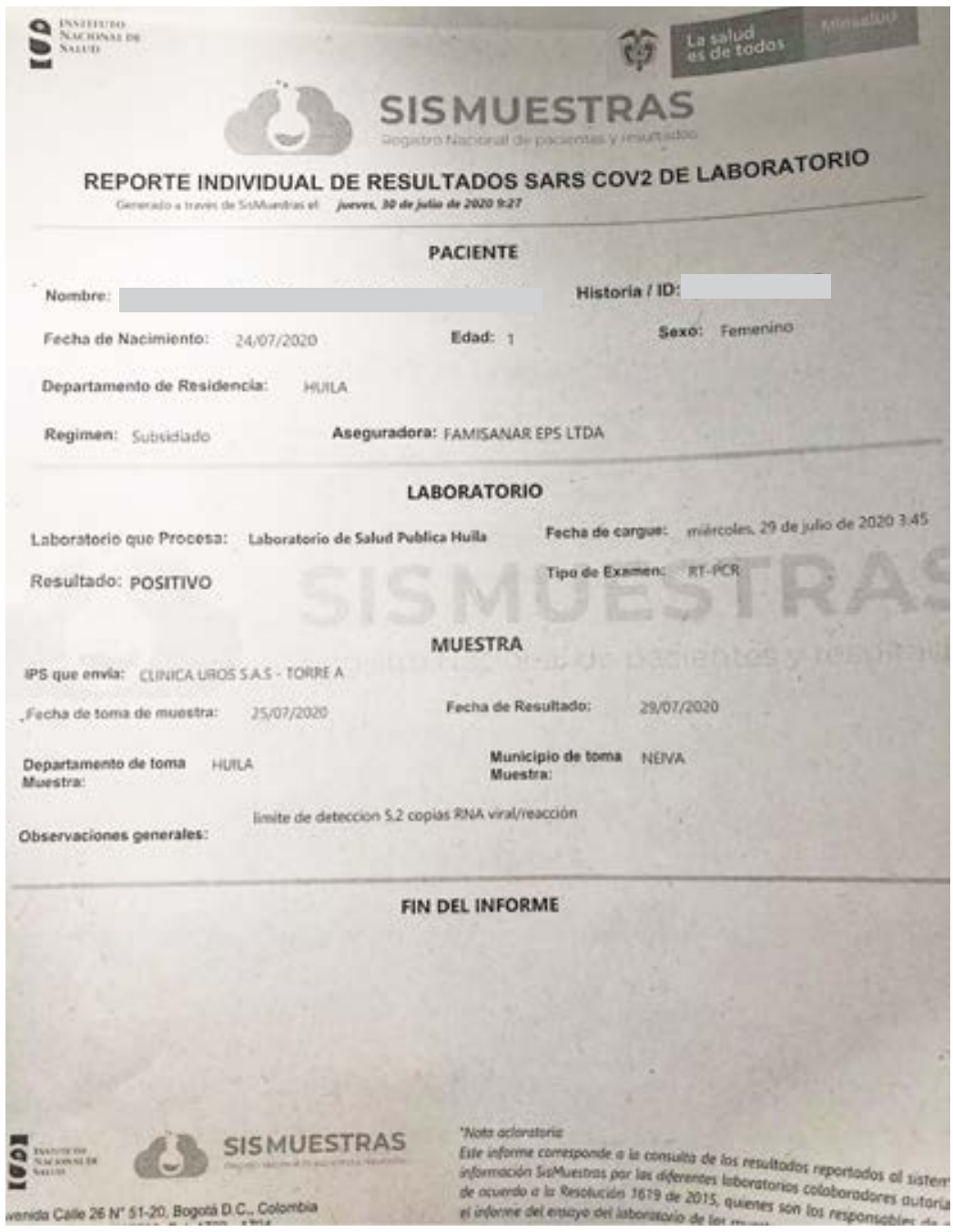

